\title{
Discussion on evaluation and improvement technology of sewage biodegradability
}

\author{
Qi Qiu, ${ }^{1,2}$ Yue Wang, ${ }^{1}$ and Li ping Qiu ${ }^{1 *}$ \\ ${ }^{1}$ School of Civil Engineering and Architecture, University of Jinan, 336 Nanxinzhuangxi Road, Jinan, 250022, China. \\ ${ }^{2}$ School of Environmental and Municipal Engineering, Lanzhou Jiaotong University, 88 Anningxi Road, Lanzhou, 730070, China.
}

\begin{abstract}
The lack of water resource and the increasing water pollution have become bottleneck which restricted social progress and economic development. The amount of municipal sewage is large and the pollution is relatively light, so it has a significant potential for recovery and recycle from municipal wastewater. As the most widely used of wastewater denitrification technology in the current water treatment industry, biological denitrification efficiency has been shackled by the lack of inflow carbon source and low $\mathrm{C} / \mathrm{N}$ ratio. To solve the issue of insufficient carbon source and low nitrogen removal efficiency of traditional biological denitrification technology, the paper summarized the concept, evaluation methodology and significance of biodegradability, several typical techniques for elevating biodegradability also have been mentioned. It will provide reference for process selection in improving the biodegradability of wastewater through analyzing their advantages and disadvantages in the application process.
\end{abstract}

\section{Introduction}

In recent years, the issue of water eutrophication has become increasingly prominent, and a series of incidents caused by it have affected the daily life of residents seriously. Nitrogen and phosphorus are the main factors that cause the water eutrophication. Therefore, it is significant to discharge nitrogen and phosphorus below standard in particular. Biological denitrification technology is the most widely used technology of wastewater denitrification, pollutants are degraded and wastewater is purified by making use of the metabolic action of microorganisms, and the sufficient carbon source is the key for denitrifying bacteria to efficient denitrification. Kuba [1] proposed that it was necessary to add the external carbon source to guarantee the biological denitrification effect when the $\mathrm{C} / \mathrm{N}$ ratio of influent is less than 3.4. However, the $\mathrm{C} / \mathrm{N}$ ratio of chemical wastewater, aquaculture wastewater, landfill leachate and domestic sewage of some cities are most lower than this value. In the actual project, methanol or ethanol have usually been added to the low $\mathrm{C} / \mathrm{N}$ ratio wastewater in order to achieve the high efficiency of nitrogen removal. But in this way, the limited organic resources have been consumed and the running cost of the sewage plant has increased. It will be the emphasis of this paper to improve the $\mathrm{C} / \mathrm{N}$ ratio of sewage and enhance its biodegradability on the purpose of achieving the goal of efficient nitrogen without adding external carbon.

\footnotetext{
* Corresponding author: lipingqiu@163.com
}

\section{Overview of wastewater biodegradability}

\subsection{The definition of wastewater biodegradability}

The wastewater biodegradability is one of the important characteristics of wastewater, which means that the difficulty of organic pollutants have been degraded by microorganism. The substance of the wastewater biodegradability is pointed that the chemical structure of pollutants in the wastewater have been changed through the metabolism of microorganisms, thus achieving the degree of chemical and physical properties of pollutants [2].

The purpose of studying the biodegradability of pollutants is to understand whether the molecular structure of the pollutants can be decomposed to the environment acceptable structure and the speed of decomposition is fast enough to help the biological treatment process and improve the efficiency of treatment.

\subsection{The assessment of wastewater biodegradability}

\subsubsection{Method of aerobic respiration}

The aerobic biodegradation process of organic matter is accompanied by the consumption of $\mathrm{O}_{2}$ and the generation of $\mathrm{CO}_{2}$ [3].The biodegradability of pollutants 
(or wastewater) can be determined by measuring changes with the concentration of $\mathrm{O}_{2}$ or $\mathrm{CO}_{2}$ in the process of respiratory metabolism.

The method of $\mathrm{BOD}_{5} / \mathrm{COD}_{\mathrm{Cr}}$ ratio is the most classical method to evaluate the biodegradability of wastewater. The main advantage of this method is that the determination methods of BOD and COD are mature, and the equipment for analysis is simple relatively. However, the turnaround time of BOD is long, and the temperature, $\mathrm{pH}$ value and other factors will also lead to errors in measurement. In addition, the measured value of COD also includes some inorganic reductive substances (such as $\mathrm{S}^{2-}, \mathrm{SO}_{4}{ }^{2-}$, etc.) , which can not reflect the content of organic pollutants in the wastewater accurately. Therefore, the traditional $\mathrm{BOD}_{5} / \mathrm{COD}_{\mathrm{Cr}}$ ratio method could not adapt to the requirements of modern production and scientific research any more.

TOC, TOD and other indicators could reflect the concentration of organic pollutants in wastewater better than COD, and these indicators are able to be measured by analysis instruments fastly. As a result, TOC, TOD and other indexes have begun to replace COD in recent years.

\subsubsection{Determination of microbial quantity or activity method}

After the contaction between microorganism and wastewater, the biodegradability of wastewater could be reflected by observing the variation about quantity or activity of microorganism indirectly. Due to essence of microbial decomposition is dehydrogenation, we could make use of the activity of dehydrogenase as an indicator to evaluate the ability for microorganism to decompose pollutants [4]. If the activity of dehydrogenase increases in culture medium with certain pollutants, it indicates that microorganisms can degrade the pollution. Adenosine triphosphate (ATP) is a kind of material for energy storage, so ATP content could be used as an indicator to evaluate the ability of microorganisms to catabolize pollutants

Although the dehydrogenase activity and ATP content have already been measured in kinds of mature methods, due to the complex operation and various instruments and drugs, these two methods are mainly used in scientific research.

\subsubsection{Direct evaluation method}

This is a method to determine the feasibility of biological treatment of wastewater by measuring the removal efficiency of pollutants. It can be determined by shaking table test and biochemical model test specifically.

The concrete operation of the shaking table test is to add appropriate $\mathrm{N}, \mathrm{P}$ and other nutrients to the certain pollutant (or waste water) in a series of erlenmeyer flasks, adjust the $\mathrm{pH}$ value and inoculate one or more microorganisms(which can be acclimated active sludge) into the bottle. Eventually the bottles are oscillated in the shaking table.
The variation of physical appearance of the culture medium(concentration, color, smell, etc.), the variation of microorganism (bacteria, biomass, biofacies, etc.) and chemical composition $(\mathrm{pH}, \mathrm{COD}, \mathrm{BOD}$ or the concentration of pollutants).

The biochemical model test was carried out in a biochemical reactor model (such as aeration tank model). The removal efficiency of the different sewage treatment facilities and the influence of sewage biological treatment could be predicted through simulating reaction conditions (MLSS, temperature, DO, F/M ratio, etc.) of actual sewage treatment facilities (such as aeration tank) in the biochemical model. Therefore, the model test was suitable to illustrate the feasibility of biological treatment of wastewater accurately.

\subsection{The significance of improving wastewater biodegradability}

Wastewater treatment is an important part of environmental protection engineering, and biological method plays an significant role in sewage treatment $[5$, [6]. The feasibility and effectiveness of biological treatment of wastewater is judged by its biodegradability [7, [8]. The biodegradability of wastewater refers to the ability of contaminants to be deposited and utilized. Researching the biodegradability of wastewater has great significance to enhance biological treatment effect and the selection of treatment processes.

\section{Common methods to improve the biodegradability of sewage}

\subsection{Ozone pretreatment}

The combined of ozone and biological treatment can improve the removal efficiency of persistent organic pollutant, the biodegradability of wastewater improved by Ozone peroxidation, and the persistent organic pollutant would be removed by the subsequent biological treatment $\quad[9, \quad[10]$. The heterogeneous catalytic oxidation process made use of solid catalyst to produce more intermediate products (such as hydroxyl $\operatorname{radical} \cdot \mathrm{OH}$ ) and accelerate the oxidation of liquid phase (or gas phase), in order to make the molecular structure of organic compounds change from complex to simple, thus achieving the purpose of increasing the biodegradability of wastewater [11].

Yang [12] investigated the improvement of ozone on the biodegradability of secondary effluent through ozonizing the different kind of secondary effluent from 3 typical WWAP in Beijing. To adjust ozone dosing time to control ozone concentration at 2, 4, 6, 8 and $10 \mathrm{mg} / \mathrm{L}$ for batch test method. The results showed that $\mathrm{UV}_{254}$ and SUVA (UV 254 /DOC) decreased with the increase of ozone dosage, UV254 and SUVA reduced more than 54.4\% and $56.6 \%$ respectively when the dosage of ozone was 6 $\mathrm{mg} / \mathrm{L} ; \mathrm{BOD}_{5} / \mathrm{COD} 、 \mathrm{BDOC}$ and BDOC/DOC enhanced more than $30 \%, 360 \%$ and $360 \%$, respectively. It was indicated that proper ozone dosage could improve the 
biodegradability of secondary effluent.

\subsection{Pretreatment of Fenton reagent}

Fenton technology is widely used in refractory wastewater treatment because of its good treatment effect, low cost and simple operation. Fenton reagent is the combination of $\mathrm{Fe}^{2+}$ and $\mathrm{H}_{2} \mathrm{O}_{2}$. The origin of Fenton reagent was that French scientist Fenton discovered $\mathrm{Fe}^{2+}$ and $\mathrm{H}_{2} \mathrm{O}_{2}$ could be mixed in a specific ratio to oxidize tartaric acid effectively under acid conditions in 1894 [13]. Therefore, the reaction involved Fenton reagent is also known as Fenton reaction because his discovery lays the foundation for Fenton reagent in wastewater treatment [14]. The Fenton reaction was first used in wastewater treatment until 1964, Canadian scholar Eisenhouser used the Fenton method to treat phenol and alkyl wastewater and achieve good results [15].

Up to now, Fenton method as an advanced oxidation technology has been widely applied in improving the biodegradability and reducing COD of wastewater [16, [17, [18]. Ming [19] adopted Fenton agent to enhance the biodegradability of the pesticide wastewater, the initial COD concentration was $676.8 \mathrm{mg} / \mathrm{L}$, the dosage of $\mathrm{H}_{2} \mathrm{O}_{2}$ and $\mathrm{FeSO}_{4} \cdot 7 \mathrm{H}_{2} \mathrm{O}$ were $0.4 \mathrm{~mol} / \mathrm{L}$ and $10 \mathrm{~g} / \mathrm{L}$ with the reaction condition $\left(\mathrm{pH}=3, \mathrm{~T}=25^{\circ} \mathrm{C}\right)$, and shaking speed was $160 \mathrm{r} / \mathrm{min}$. After $60 \mathrm{~min}$ reaction, the COD removal efficiency of wastewater reached $83.9 \%$, and $\mathrm{BOD}_{5} / \mathrm{COD}$ increased from 0.075 to 0.92 . In 2004, Pala and Erden [20] treated garbage leachate with COD 22400 $\mathrm{mg} / \mathrm{L}$ by Fenton method. The COD removal efficiency reached $79 \%$ under the condition that the dosage of $\mathrm{H}_{2} \mathrm{O}_{2}$ and $\mathrm{Fe}^{2+}$ were all $2500 \mathrm{mg} / \mathrm{L}$. Huseyin Tekin [21] studied the treatment effect of Fenton reagent on 10 kinds of pharmaceutical wastewater. The initial COD concentration and $\mathrm{pH}$ value were $900-7000 \mathrm{mg} / \mathrm{L}$ and 3.5 , the dosage of $\mathrm{H}_{2} \mathrm{O}_{2}$ and $\mathrm{Fe}^{2+}$ were 5 and $0.32 \mathrm{~mol} / \mathrm{L}$, respectively $\left(\mathrm{T}=50^{\circ} \mathrm{C}\right)$.

\subsection{Photocatalytic oxidation (PCO)}

Photocatalysis technology has begun to attract people's attention and become the leader in emerging environmental protection technology in 1970s. The beginning of photocatalytic research came from the paper from Fujishima [22] in 1972, which was published on Nature about producing hydrogen by photocatalytic water-splitting with the use of emiconductor metal oxide $\mathrm{TiO}_{2}$. From then on, people has begun to pay attention to the field of photocatalysis and realized the wide application of photocatalytic technology.

The light conditions of photocatalytic technology $(\mathrm{k}<$ $390 \mathrm{~nm}$ ) are easier to be realized and less affected by other factors. Becides, the photocatalyst is non-toxic, harmless, non corrosive, stable and reusable, which determine its broad application prospect and powerful market development.

In view of the shortcomings of photocatalytic method, scientists have begun to combine photocatalytic oxidation with other methods to achieve high efficient and deep processing. Cui [15] studied on the treatment of refractory organic compounds in fermented wastewater by $\mathrm{UV} / \mathrm{O}_{3}$ catalytic oxidation process, the results showed that both activated carbon and titanium dioxide could obviously accelerate the reaction efficiency. It can not only increase the removal rate of COD, but also shorten the reaction time, and the synergistic effect of activated carbon and $\mathrm{TiO}_{2}$ was better. The research of Yan [23] about the combined treatment of Ultrasonic wave- $\mathrm{TiO}_{2}$ photocatalysis in treating landfill leachate indicated that: When the dosage of $\mathrm{TiO}_{2}$ powder was $2 \mathrm{~g} / \mathrm{L}$ and $\mathrm{pH}$ value was 11 , the ultrasonic radiation of $292.5 \mathrm{~W}$ was first used for $3 \mathrm{~min}$, and then irradiated with high pressure mercury lamp (250W) in $3 \mathrm{~min}$. The removal efficiency of COD and ammonia in the leachate were $50.1 \%$ and $75 \%$, respectively.

The combination of photocatalysis and biological methods has attracted more and more researchers' attention in many combined treatments. As a strong oxidizing technology, photocatalytic oxidation method could mineralize some refractory organic matter, thus it is conducive to bioavailability and degradation. At present, the combination of photocatalysis and biological has obtained good effect. Parra [24]employed the combination of photocatalysis and biological process to treat isoproturon wastewater, after proceeding photocatalytic pretreatment for $1 \mathrm{~h}$, the BOD5/COD ratio of isoproturon solution $(0.2 \mathrm{mM})$ increased from 0 to 0.65 , it was an appropriate method to enhance the biodegradability of the wastewater.

\section{Conclusion}

The testing methods and standards of biodegradability are facing the technological innovation. With the progress of science and technology, a large number of new instruments have emerged constantly, and the measurement of various water quality indicators were more accurate and convenient. Unlike the traditional $\mathrm{BOD}_{5} / \mathrm{COD}_{\mathrm{cr}}$, TOC and TOD are better than COD to reflect the concentration of organic pollutants in the wastewater. It is a kind of trendency for these indicators to replace COD.

Ozone preoxidation is still the most widely way to improve the biodegradability in the field of water treatment. The principle of photocatalytic oxidation is a hot spot in recent years. The mechanism from the improvement of biodegradability still need to be explored.

There are many ways to enhance biodegradability. It will be the innovative research direction in this field about combining different treatments and improving the biodegradability synergistically.

\section{Acknowledgement}

This work was financially supported by the National Science Foundation of China (51678276), the key research and development program of Shandong Province (2016CYJS07A03-3, 2016GSF117012, 
2018GSF117026) and the Shandong Provincial Natural Science Foundation (ZR2018BEE040).

\section{Reference}

1. T. Kuba, M. C. M. V. Loosdrecht and J. J. Heijnen, Phosphorus and nitrogen removal with minimal COD requirement by integration of denitrifying dephosphatation and nitrification in a two-sludge system Water Res. 30 1702(2016)

2. C.O'neill, F. R. Hawkes, D. L. Hawkes, S. Esteves and S. J. Wilcox, Anaerobic-aerobic biotreatment of simulated textile effluent containing varied ratios of starch and azo dye Water Res. 34 2355(2000)

3. P. Yang, Test Technology of Biochemical Trait for Industrial Effluent Chem Eng. (2002)

4. W. Han, Feasibility Study on the Assessing Approaches of Wasterater's Biodegradability Jiang Su Environ Sci \& Technol (2004)

5. Y.Tong and P. L. Bishop Stratification of microbial metabolic processes and redox potential change in an aerobic biofilm studied using microelectrodes WATER Sci\& Technol 37 195(1998)

6. M. I.Beydilli, S. G. Pavlostathis and W. C. Tincher, Biological Decolorization of the Azo Dye Reactive Red 2 under Various Oxidation-Reduction Conditions Water Environ. Res. 72 698(2000)

7. O'neill C., A. Lopez, S. Esteves, F. R. Hawkes, D. L. Hawkes and S. Wilcox, Azo-dye degradation in an anaerobic-aerobic treatment system operating on simulated textile effluent Appl Micrebiol Biot $\mathbf{5 3}$ 249(2000)

8. K. C. A. Bromley-Challenor, J. S. Knapp, Z. Zhang, N. C. C. Gray, M. J. Hetheridge and M. R. Evans, Decolorization of an azo dye by unacclimated activated sludge under anaerobic conditions Water Res. 34 4410(2000)

9. C. W.Lee, S. D. Bae, S. W. Han and L. S. Kang Application of ultrafiltration hybrid membrane processes for reuse of secondary effluent DESALINATION 202 239(2007)

10. J.Arévalo, G. Garralón, F. Plaza, B. Moreno, J. Pérez and M. Á. Gómez, Wastewater reuse after treatment by tertiary ultrafiltration and a membrane bioreactor (MBR): a comparative study DESALINATION 243 32(2009)

11. S.Wang, J. Ma, B. Liu, Y. Jiang and H. Zhang, Degradation characteristics of secondary effluent of domestic wastewater by combined process of ozonation and biofiltration $J$ Hazard Mater 150 109(2008)
12. A. M Yang., J. Chang, Y. P. Gan, Y. Z. Peng, S. J. Zhang and C. L. Meng, Research on the organic biodegradability of secondary effluent treated by ozonation Environ Sci 31 363(2010)

13. H. J. H. Fenton LXXIII.-Oxidation of tartaric acidinpresence of iron J Chem Soc T 65899

14. E. Neyens and J. Baeyens, A review of classic Fenton's peroxidation as an advanced oxidation technique $J$ Hazard Mater 98 33(2003)

15. C. Longzhe, Research on the treatment of hard degradation organic in fermantative wastewaterby $\mathrm{UV} / \mathrm{O}^{3}$ catalytic oxidation Elect Power Environ Prot (2004)

16. N. D. L.Cruz, R. F. Dantas, J. Giménez and S. Esplugas, Photolysis and $\mathrm{TiO}_{2}$ photocatalysis of the pharmaceutical propranolol: Solar and artificial light Applied Catal B Environ 130 249(2013)

17. Y. Segura, F. Martínez, J. A. Melero, R. Molina, R. Chand and D. H. Bremner, Enhancement of the advanced Fenton process $\left(\mathrm{Fe} 0 / \mathrm{H}_{2} \mathrm{O}_{2}\right)$ by ultrasound for the mineralization of phenol Applied Catal $B$ Environ 113-114 100(2012)

18. D.Hou, R. Goei, X. Wang, P. Wang and T. T. Lim, Preparation of carbon-sensitized and Fe-Er codoped TiO 2 with response surface methodology for bisphenol A photocatalytic degradation under visible-light irradiation Applied Catal B Environ126 121(2012)

19. C. Ming, K. Tian and L. Zhu, Pretreatment of cartap pesticide wastewater by Fenton reagent Chin J Environ Eng 8 5135(2014)

20. A. Palaand G. Erden, Chemical Pretreatment of Landfill Leachate Discharged into Municipal Biological Treatment Systems Environ. Eng. Sci. 21 549(2004)

21. H.Tekin, O. Bilkay, S. S. Ataberk, T. H. Balta, I. H. Ceribasi, F. D. Sanin, F. B. Dilek and U. Yetis, Use of Fenton oxidation to improve the biodegradability of a pharmaceutical wastewater $J$ Hazard Mater 136 258(2006)

22. A. Fujishima and K. Honda, Electrochemical photocatalysis of water at semiconductor electrode NATURE 238(1972)

23. F. Yan, G. Xiao and W. Pan, Treatment of landfill leachate by coupling system of titanium dioxide and ultrasonic Chin J Environ Eng 4 383(2010)

24. S.Parra, S. Malato and C. PulgarinNew integrated photocatalytic-biological flow system using supported $\mathrm{TiO}$ and fixed bacteria for the mineralization of isoproturon Appl Catal B Environ 36 131(2002) 